\title{
Maternal and neonatal outcomes following trial of labor after two previous cesareans: a retrospective cohort study.
}

\author{
Reut Rotem ${ }^{1}$, Ayala Hirsch ${ }^{1}$, Hen Sela ${ }^{1}$, Arnon Samueloff ${ }^{1}$, Sorina Grisaru-Granovsky ${ }^{1}$, \\ and Misgav Rottenstreich ${ }^{2}$ \\ ${ }^{1}$ Shaare Zedek Medical Center \\ ${ }^{2}$ Shaare Zedek Medical Center
}

July 2, 2020

\begin{abstract}
Objective: To evaluate the maternal and neonatal outcomes of parturients attempting trial of labor (TOL) after two previous cesarean deliveries (CD) Design: A retrospective computerized database cohort study. Setting: A single tertiary center between 2005 and 2019. Population: Parturients attempting TOL after two CD were compared to parturients opting for elective third repeat CD. TOL after two CD was allowed only for those who met all the criteria of our departments' protocol. Methods: A univariate analysis was conducted and was followed by a multivariate analysis. Main outcome measures: A composite of adverse maternal and neonatal outcomes. Results: A total of 2719 eligible births following two CD were identified, of which 485 (17.8\%) had attempted TOL. Overall, successful vaginal delivery rate following two CDs was $86.2 \%$. Uterine rupture rates were higher among those attempting TOL $(0.6 \%$ vs $0.1 \% \mathrm{p}=0.04)$. However, rates of hysterectomy, re-laparotomy, blood product infusion and intensive care unit admission did not differ significantly between the groups. Neonatal outcomes following elective repeat CD were less favorable (specifically, neonatal intensive care unit admission and composite adverse neonatal outcome). Nonetheless, when controlling for potential confounders, an independent association between composite adverse neonatal outcome and an elective repeat $\mathrm{CD}$ was not demonstrated. In a subgroup analysis, diabetes mellitus and hypertensive disorders of pregnancy were found independently associated with failed TOLAC. Conclusion: When following a strict protocol, TOL after two CD is a reasonable alternative and associated with favorable maternal and neonatal outcomes
\end{abstract}

\section{Introduction}

Rates of cesarean deliveries (CD) have substantially increased in recent decades to approximately $21 \%$ of births worldwide ${ }^{1}$ with the most common indication for CD being a previous uterine scar ${ }^{2}$. Repeat CD is associated with significant morbidities including: the need for blood transfusion, bowel and bladder injury and placenta previa with its related complications ${ }^{3,4}$. In 1980, the National Institute of Child Health and Human Development Conference on Childbirth concluded that vaginal delivery (VD) after a CD is a relevant alternative. Successful vaginal birth after CD (VBAC) compared to elective repeat CD is associated with fewer complications. However, a failed trail of labor after CD (TOLAC) is associated with serious complications. Therefore, efforts are made in order to identify the best candidates for TOLAC ${ }^{5}$. The American College of Obstetrics and Gynecology (ACOG) committee opinion from 1994 on the issue of TOLAC stated that TOLAC after two or more previous CDs should not be discouraged. ${ }^{6}$ Thereafter, institutions consented and allowed TOLAC following two previous $\mathrm{CD}^{7-10}$. Subsequently, the ACOG guidelines from $2019^{11}$ maintains that it is reasonable to consider parturients with two previous low segment transverse (LSTCS) CD as appropriate candidates for TOLAC following a thorough individual consultation assessing their previous and current obstetrical history and their probability of achieving a successful VBAC.

Initiated in 2000, our medical center follows a strict protocol regarding TOLAC in parturients who previously had $2 \mathrm{CD}$. There is a paucity of data regarding maternal and neonatal risks associated with TOLAC in this 
specific population. The purpose of this study was to investigate the outcomes of TOLAC following two CD versus a third repeat elective CD and to explore factors associated with successful TOLAC.

\section{Methods:}

In this retrospective cohort study all parturients at the Shaare Zedek Medical Center (SZMC) with a history of two previous CD between August 2005 and November 2019, were enrolled. We included parturients between 24-42 weeks of gestations who had two prior CDs and subsequently had vaginal vertex births and parturients who chose to have a repeat elective CD. Excluded from the study were parturients with nonvertex presentation, placenta previa, placenta accrete, mullerian uterine anomalies, multifetal gestation other than twins and parturients without at least one previous vaginal delivery. A comparison was made between those who attempted TOLAC and those who were scheduled for an elective repeat CD.

In general, our department's standard recommendation following previous two CD is to undergo an elective repeat CD. However, TOLAC is discussed with those parturients who express interest in attempting labor after CD. TOLAC is discussed only if all the following criteria are validated. The criteria are as follows: 1. The parturient explicitly expresses her request for TOLAC and comprehends the potential risks, benefits, and alternatives. 2. The parturient had a previous vaginal delivery (VD), either before, between or after the second CD. 3. Both previous uterine incisions were low segment transverse, there were no extensions or severe adhesions. 4. Fetal estimated weight is $<4000$ grams. 5. Vertex presentation. Additionally, the onset of labor must be spontaneous, we do not induce or augment labor in parturient with 2 previous CD. SZMC's medical record database on all labor and deliveries is updated in real time during labor and delivery by attending healthcare professionals and audited periodically by trained technical personnel to ensure validity of the data. Over $95 \%$ of Israeli citizens' medical care is covered by the Israeli National Health Plan hence continuity of care is granted for long periods of time for most of the patients. Maternal and neonatal records were reviewed and retrieved for relevant data, information was coded and identifiable, and personal information for each patient was protected by anonymization prior to analysis.

Definitions: The terms used were defined as the following: Uterine rupture - complete uterine scar ruptures, i.e. involving the occurrence of a full-thickness defect with direct connection between peritoneal space and the uterine cavity. Diagnosis was made by an attending physician during an explorative laparotomy. Re-laparotomy -additional abdominal operation performed during hospitalization for delivery ${ }^{12}$ Postpartum hemorrhage (PPH): Was defined using one of the two following definitions: 1. Estimated blood loss of over $500 \mathrm{ml}$ in vaginal delivery (VD) and over $1000 \mathrm{ml}$ in $\mathrm{CD}^{13}$ (In SZMC pads are weighted following $\mathrm{VD}$, but in some cases when pads or weighting is not feasible blood loss is estimated subjectively by the midwife/obstetrician); 2. the transfusion of blood products and/or hemoglobin drop $>4 \mathrm{gr} / \mathrm{dL}$.Prolonged hospitalization : $>5$ days for vaginal deliveries and $>7$ days for cesarean deliveries.

Primary outcome was defined as a composite adverse maternal outcome : one or more of the following: PPH, hemoglobin drop $>4 \mathrm{gr} / \mathrm{dL}$, blood products transfusion, intensive care unit (ICU) admission.Secondary outcomes were defined as follows: 1. Composite adverse neonatal outcome : a composite outcome of one or more of the following: 5-min Apgar score $<7$, neonatal asphyxia, neonatal intensive care unit (NICU) admission, and the need for mechanical ventilation.

2. Composite adverse maternal and neonatal outcome s among the group of parturients attempting TOLAC. We compared those who achieved VBAC and those whose attempt at labor was aborted and necessitated in labor CD

Statistical analysis : An initial univariate analysis was carried out, categorical variables were presented as a percentage and compared using Chi square and Fisher's exact test as appropriate. Continuous variables presentation was according to each variable distribution, while normal distributed variables were presented as a mean and standard deviation, those displaying non-normal distribution were presented as median with interquartile range. A comparison was made using Student's t-test and Mann Whitney test, accordingly. All analyses were two sided and a p value $<0.05$ was considered statistically significant. Data analysis was conducted according to the group category to which the parturient was initially categorized corresponding to 
her original request. For instance, if a parturient originally requested an elective CD and presented in active labor, resulting in an emergency CD, she remained in the analysis of the planned elective CD group. However, all parturients analyzed in the TOLAC group attempted TOL even if the result was CD. A multivariate analysis using a binary logistic regression model was used in order to account for the independent association between composite adverse neonatal outcomes, infusion of blood products and TOLAC versus elective CD after 2 CDs. Adjusted Odds Ratios (aOR) and 95\% confidence intervals (CI) were computed. A sub-group analysis comparing in-labor CD (=failed TOLAC) versus successful VBAC was conducted. A univariate analysis was followed by a multivariate analysis in order to examine independent factors associated with TOLAC failure.

Data analysis was carried out using SPSS software (version 23 statistical package; IBM, Armonk, NY). The study was approved by the local institutional ethics committee in accordance with the principles of the Declaration of Helsinki (IRB: 001-20-SZMC).

\section{Results:}

During the study period, 3141 eligible births were identified, of which 422 were excluded in accordance with our exclusion criteria. According to our study inclusion criteria, all parturients with previous 2 CD experienced a previous vaginal delivery. Of the remaining 2719 deliveries, 485 (17.8\%) parturients attempted TOLAC and the remaining $2234(82.2 \%)$ had a scheduled elective repeat CD. (Figure 1). Among the 485 parturients attempting TOLAC, 418 achieved vaginal delivery $(86.2 \%)$, with $26(26 / 418,6.2 \%)$ assisted by operative VD. The remaining $13.8 \%$ experienced failed TOLAC and required in labor CD.

Table 1 displays various demographic and obstetrical characteristics of the study groups. Parturients who had requested an elective repeat CD were significantly younger and of lower gravidity and parity order. In addition, they had higher rates of conception using advanced reproductive technology, diabetes (pregestational and gestational) and hypertensive disorders of pregnancy.

\section{Maternal outcomes:}

Selected maternal outcomes as well as the mode of delivery are presented in Table 2 . Our primary outcome - composite adverse maternal outcome rate was similar in both groups; $6.2 \%$ of the parturients attempting TOL vs. $4.8 \%$ of the parturients who had elective repeat $\mathrm{CD}(\mathrm{p}=0.2)$.

However, several differences were noted: rates of uterine rupture were lower among those who had elective repeat $\mathrm{CD}(0.1 \%$ vs. $0.6 \%, \mathrm{p}=0.04)$. Overall, there were six cases of uterine rupture $(0.22 \%)$ three in each group. All three cases of uterine rupture among parturients who intended to have an elective CD occurred before active labor, during the latent phase. They all presented with abdominal pain prior to their scheduled elective date and underwent surgery without delay. Among parturients attempting TOL two out of three cases of uterine rupture occurred in the latent phase. These parturients presented with fetal distress or abdominal pain. One case was diagnosed unexpectedly post-partum during a revision of the uterine cavity due to retained placenta. Hysterectomy rate also did not differ between the groups. Hysterectomy was the outcome of DIC following sepsis or pre-eclampsia. Only one of the cases of hysterectomy was due to uterine rupture. A non-significant trend of higher rates of re-laparotomy after CD was shown among those who had a planned repeat CD. However, there were only three cases of re-laparotomy, all of which were in the group of elective repeat CD. In two of the cases an internal abdominal bleeding was detected and the third was due to an eventration of the small intestine through the Pfannenstiel incision.

There were no differences in the rates between the groups of endometritis, $\mathrm{PPH}$, hemoglobin drop[?]4 gr/dL and blood products, prolonged hospitalization, and ICU admission.

\section{Neonatal Outcomes}

Neonatal outcomes are presented in Table 3 . Parturients who had elective repeat CD were scheduled for surgery notably earlier than the TOLAC group and the neonatal birth weights were significantly lower. Consequently, rates of macrosomia neonates were significantly lower in the elective repeat CD group. One- 
Minute Apgar score $<7$ was considerably more prevalent among those attempting TOLAC. Rates of NICU admission were higher among those who had elective repeat CD. However, 5-minute Apgar scores, TTN, neonatal asphyxia and mechanical ventilation were comparable between the two groups. Overall, rates of the composite adverse neonatal outcome were significantly higher among those who had planned an elective repeat $\mathrm{CD}(11.0 \%$ vs. $6.2 \%, \mathrm{p}<0.01)$.

Table 4 displays the results of a multivariate regression model which was conducted in order to account for independent factors associated with composite adverse neonatal outcome. Attempting TOLAC was not independently associated (aOR 0.48, 95\% CI 0.22-1.04) with composite adverse neonatal outcomes while failed TOLAC was found to be independently associated with composite adverse neonatal outcome (aOR $6.08,95 \%$ CI $2.19-16.90)$

\section{Failed TOLAC:}

Table S1 presents selected maternal and delivery characteristics and outcomes of parturients attempting TOL following $2 \mathrm{CD}$ according to the actual mode of delivery. Parturients with failed TOLAC (67/485) were of lower gravidity and parity order with higher rates of multifetal gestation. Rates of macrosomia did not differ between the groups. All parturients planning TOLAC with multifetal gestation failed (4/4). Rates of composite adverse maternal and neonatal outcomes were significantly higher among those who had failed TOLAC ( $11.9 \%$ vs. $5.3 \%$ and $29.9 \%$ vs $2.4 \%$, respectively, $\mathrm{p}<0.01$ for both). A multivariate analysis controlling for parity, diabetes, hypertensive disorder of pregnancy and epidural usage had demonstrated an independent association between failed TOLAC and composite adverse maternal outcome (aOR 2.55, 95\% CI 1.05-6.22). An additional multivariate analysis controlling for diabetes, hypertensive disorder of pregnancy, gestational age at birth and neonatal birth weight demonstrated an independent association between failed TOLAC and composite adverse neonatal outcome (aOR 7.05, 95\% CI 2.60-19.05). When assessing factors associated with failed TOLAC, diabetes and hypertensive disorders of pregnancy were found positively associated (aOR 3.13, 95\% CI 1.30-7.70 an aOR 8.45, 95\% CI 2.09-34.12, respectively) while epidural was found to be negatively associated (aOR $0.42,95 \%$ CI $0.24-0.75$ ); an association to parity and gravidity was not demonstrated.

Discussion In this retrospective cohort study, maternal and neonatal outcomes were compared between parturients with a history of previous two CD attempting TOL versus those who had scheduled a third elective CD. Seventeen percent of parturients with two previous CD met our protocol criteria and expressed their preference for TOLAC. VBAC rates were overall high (86\%). Parturients attempting TOL had higher rates of uterine rupture with an overall rate of $0.6 \%$; otherwise maternal outcomes were comparable. Failed TOLAC was found independently associated with composite adverse neonatal outcome, in addition to diabetes mellitus and hypertensive disorders of pregnancy.

Previous studies have described an array of VBAC rates following two CD, ranging between $66-75 \%{ }^{10,14-16}$, with a pooled rate of $71 \%{ }^{17}$. Our VBAC success rates (86\%) are higher than those described in the literature. It is possible that this is related to our department's protocol which requires previous vaginal delivery and spontaneous onset of labor which were proven to be the best predictors for VBAC. ${ }^{18}$

Previous studies were inconclusive regarding maternal results associated with TOLAC. Some studies ${ }^{15}$ indicated a two-fold increase in the risk of composite maternal morbidity, including uterine rupture, bladder injury, or other major operative injuries, while others ${ }^{17}$ demonstrated comparable outcomes between the groups. Our study demonstrated a non-significant lower rate of blood transfusion, re-laparotomy, and hysterectomy in the TOLAC group. This result was demonstrated in previous studies ${ }^{7,15,17}$ and most probably reflects the increased risk inherent to multiple $\mathrm{CD}^{19,20}$. Previous studies ${ }^{15149}$ demonstrated rates of uterine rupture following two or more previous CD ranging between $0.8 \%-3.7 \%$ and concluded that uterine rupture was significantly more common in those attempting TOLAC in comparison to those who chose repeat elective $\mathrm{CD}$. On the other hand, one ${ }^{16}$ retrospective study did not demonstrate a significant difference in uterine rupture. A meta-analysis ${ }^{17}$ determined a pooled risk of $1.36 \%$ for a uterine rupture in TOLAC after two CD. Our data indicated an absolute risk of $0.6 \%$ for uterine rupture when attempting TOL which is 
significantly higher when compared to an elective CD (0.6\% vs. $0.1 \%, \mathrm{p}=0.04)$ but it is to our knowledge, the lowest rate described in literature and does not differ significantly from the risk described for TOL following one $\mathrm{CD}^{21}$. The relatively lower rates of uterine rupture along with the remarkable high VBAC rate might be attributed to several factors related to our departmental protocol: 1. In our institution, labor was not induced nor augmented, unlike previous studies in which $65 \%$ of parturients were induced ${ }^{15} 2$. In our study only parturients with prior two low segment transverse incisions were approved for TOL, unlike previous studies that included parturients with unknown scars and had higher rates of uterine rupture which reached $5.4 \%{ }^{10,14}$. 3. Previous VD is a mandatory criteria in our institution and was proven to be not only one of the best predictors for a $\mathrm{VBAC}^{22,23}$ but also a protective factor for uterine rupture ${ }^{14,15}$.

Rates of composite adverse neonatal outcomes were significantly higher among those who had an elective repeat $\mathrm{CD}$. This difference could have been explained by the difference in gestational age and higher NICU admission rates in the parturients having elective repeat $\mathrm{CD}^{24}$. However, when controlling for gestational age and other potential confounders, an independent association to an elective repeat CD was not demonstrated. Similar to our results, other studies ${ }^{4}$ showed no significant differences when comparing NICU admission and term neonatal death ${ }^{14,17}$. Not surprisingly, the rate of the composite adverse neonatal outcome was significantly higher among those who had failed TOLAC. This finding correlates with other studies that demonstrated poor 1-minute Apgar scores that were four times more common among those with a failed TOLAC. ${ }^{16}$

The ability to predict successful TOLAC is of great importance as maternal and neonatal morbidity is greater among those who fail TOLAC and require a repeat CD in labor. Our results indicated that failed TOLAC was associate with diabetes and hypertensive disorders, both of which were similarly identified as risk factors for failed TOLAC in other studies. ${ }^{4}$ In our study all parturients attempting TOLAC with multifetal gestation (4/4) failed. Due to our relatively small sample size and the fact that previous studies did not demonstrate an association between multifetal gestation and failed TOLAC, we believe that further studies are needed in order to better examine the association between the two ${ }^{18}$. Macrosomia was previous described as a predictor of a failed TOLAC ${ }^{26}$. Nevertheless, in our study rates of macrosomia were significantly higher among those attempting TOLAC while rates of macrosomia did not differ between those who achieved VBAC or failed TOLAC. Comparable to findings in a previous study ${ }^{27}$ our results raise the question of the role of macrosomia in failed TOLAC among those parturients who previously delivered vaginally. Further studies are needed in order to address this issue in groups of parturients attempting TOLAC with one previous VD.

This study holds several notable strengths: This is a large-scale population study comprising more than a third of the births in the area studied and $10 \%$ of all national births; therefore, suitable for generalization. In addition, our database is validated at real-time, which assists in eliminating potential information bias. All costs of antenatal care, birth, postpartum care for mother and child are uniformly covered by the National Health Insurance for the entire study period. Moreover, all mother-child data included were from one hospital with no transfers to other facilities. Both factors alleviate a potential selection bias; Lastly, the adherence to our strict department protocol permitted us to examine the results of a designated, relatively low-risk group of patients. Despite imposing a strict study inclusion criterion, a fair number of parturients were found eligible and attempted a relatively safe TOL.

Our study is not without limitations: A possible limitation may be due to our retrospective design and its' inherent fault. We were unable to identify and conduct a subgroup analysis of parturients who intended an elective repeat $\mathrm{CD}$ and presented in labor and hence underwent urgent surgery. Furthermore, our population has specific characteristics, particularly the motivation for large families. This may preclude in part the ability to generalize our study's results. However, we believe that most of the parturients who are interested in TOLAC following two previous CD share some characteristics in common, which may set a ground for potential partial generalization. We also recognize that our data collection process did not provide information regarding potential risk factors associated with uterine rupture, such as prior uterine closure technique, the number of previous VBAC, and an unknown number of classical uterine scars in the elective repeat CD group. Nonetheless, we did attempt to control for most recognized factors and excluded all 
identified parturients who did not meet the ACOG criteria for TOLAC ${ }^{28}$.

Conclusion : parturients with a history of two CD attempting TOLAC complying to a strict department protocol, have overall comparable and favorable maternal and neonatal outcomes. Therefore, TOL is a reasonable alternative to an elective repeated third CD. Diabetes and hypertensive disorder are associated with failed TOLAC; obstetricians should be aware of these findings when providing consultation.

Acknowledgements: We thank Pnina Mor, PhD for the critical appraisal of the manuscript and English editing.

Declaration of interest : The authors declare that they have nothing to disclose and that they have no financial or non-financial conflict of interest.

Disclosure of interests: The authors report no conflict of interest.

Funding/Support: This study was not funded.

Financial Disclosures: No financial disclosures.

Contribution to authorship: R Rotem: Protocol development, Data collection and management, Data analysis, Manuscript writing/editing.A Hirsch: Protocol development, Data collection and management, Data analysis, Manuscript writing/editing. HY Sela: Protocol development,Manuscript writing/editing.A Samueloff: Data collection and management, Manuscript writing/editingS Grisaru-Granovsky : Protocol development, Manuscript writing/editing.M Rottenstreich: Protocol development, Data collection and management, Data analysis, Manuscript writing/editing.

Ethical approval: The study was approved by the local Institutional Review Board of SZMC (IRB: 00120-SZMC, 16.12.2109). As the study was based on patient records, no informed consent was needed.

Figure legend :

Figure 1: Flow chart of the study group.

References:

1. Boerma T, Ronsmans C, Melesse DY, et al. Global epidemiology of use of and disparities in caesarean sections. Lancet . 2018;392(10155):1341-1348. doi:10.1016/S0140-6736(18)31928-7

2. Zhang J, Troendle J, Reddy UM, et al. Contemporary cesarean delivery practice in the United States. Am J Obstet Gynecol . 2010;203(4):326.e1-326.e10. doi:10.1016/j.ajog.2010.06.058

3. Silver RM, Landon MB, Rouse DJ, et al. Repeat Cesarean Deliveries. 2006;107(6):1226-1232.

4. Sandall J, Tribe RM, Avery L, et al. Optimising caesarean section use 2 Short-term and long-term effects of caesarean section on the health of women and children. Lancet . 2018;392(10155):1349-1357. doi:10.1016/S0140-6736(18)31930-5

5. Trojano G, Damiani GR, Olivieri C, et al. VBAC: antenatal predictors of success. Acta Biomed . 2019;90(3):300-309. doi:10.23750/abm.v90i3.7623

6. No R, Practice O. Vaginal delivery after a previous cesarean birth.Int J Gynecol Obstet . 1995;48(1):127129. doi:10.1016/0020-7292(95)90280-5

7. Chattopadhyay SK, Sherbeeni MM, Anokute CC. Planned vaginal delivery after two previous caesarean sections. BJOG An Int J Obstet Gynaecol . 1994;101(6):498-500. doi:10.1111/j.1471-0528.1994.tb13149.x

8. Granovsky-Grisaru S, Shaya M, Diamant YZ. The management of labor in women with more than one uterine scar: Is a repeat cesarean section really the only "Safe" option? J Perinat Med . 1994;22(1):13-17. doi:10.1515/jpme.1994.22.1.13 
9. Caughey AB, Shipp TD, Repke JT, Zelop CM, Cohen A, Lieberman E. Rate of uterine rupture during a trial of labor in women with one or two prior cesarean deliveries. Am J Obstet Gynecol . 1999;181(4):872-876. doi:10.1016/S0002-9378(99)70317-0

10. Miller DA, Diaz FG, Paul RH. Vaginal birth after cesarean: A 10-year experience. Obstet Gynecol . 1994;84(2):255-258.

11. Birth V, Cesarean A. ACOG Practice Bulletin No. 205: Vaginal Birth After Cesarean Delivery. Obstet Gynecol . 2019;133(2):e110-e127. doi:10.1097/AOG.0000000000003078

12. Patel H, Patel P, Shah DK. Relaparotomy in general surgery department of tertiary care hospital of Western India. Int Surg J . 2016;4(1):344. doi:10.18203/2349-2902.isj20164467

13. Prevention and Management of Postpartum Haemorrhage: Green-top Guideline No. 52. BJOG . 2017;124(5):e106-e149. doi:10.1111/1471-0528.14178

14. Landon MB, Spong CY, Thom E, et al. Risk of uterine rupture with a trial of labor in women with multiple and single prior cesarean delivery. Obstet Gynecol . 2006;108(1):12-20. doi:10.1097/01.AOG.0000224694.32531.f3

15. Macones GA, Cahill A, Pare E, et al. Obstetric outcomes in women with two prior cesarean deliveries: Is vaginal birth after cesarean delivery a viable option? Am J Obstet Gynecol . 2005;192(4):1223-1228. doi:10.1016/j.ajog.2004.12.082

16. Asakura H, Myers SA. More than one previous cesarean delivery: a 5-year experience with 435 patients. Obstet Gynecol . 1995;85(6):924-929. doi:10.1016/0029-7844(95)00078-6

17. Tahseen S, Griffiths M. Vaginal birth after two caesarean sections (VBAC-2) - A systematic review with meta-analysis of success rate and adverse outcomes of VBAC-2 versus VBAC-1 and repeat (third) caesarean sections. BJOG An Int J Obstet Gynaecol . 2010;117(1):5-19. doi:10.1111/j.1471-0528.2009.02351.x

18. Landon MB, Leindecker S, Spong CY, et al. The MFMU Cesarean Registry: factors affecting the success of trial of labor after previous cesarean delivery. Am J Obstet Gynecol . 2005;193(3 Pt 2):1016-1023. doi:10.1016/j.ajog.2005.05.066

19. Silver RM, Landon MB, Rouse DJ, et al. Maternal morbidity associated with multiple repeat cesarean deliveries. Obs Gynecol . 2006;107(6):1226-1232.

20. Cook JR, Jarvis S, Knight M, Dhanjal MK. Multiple repeat caesarean section in the UK: Incidence and consequences to mother and child. A national, prospective, cohort study. BJOG An Int J Obstet Gynaecol . 2013;120(1):85-91. doi:10.1111/1471-0528.12010

21. Landon MB, Hauth JC, Leveno KJ, et al. Maternal and perinatal outcomes associated with a trial of labor after prior cesarean delivery. $N$ Engl $J$ Med . 2004;351(25):2581-2589. doi:10.1056/NEJMoa040405

22. Caughey AB, Shipp TD, Repke JT, Zelop C, Cohen A, Lieherman E. Trial of labor after cesarean delivery: The effect of previous vaginal delivery. In: American Journal of Obstetrics and Gynecology . Vol 179. Mosby Inc.; 1998:938-941. doi:10.1016/S0002-9378(98)70192-9

23. Mercer BM, Gilbert S, Landon MB, et al. Labor Outcomes With Increasing Number of Prior Vaginal Births After Cesarean Delivery.Obstet Gynecol . 2008;111(2, Part 1):285-291. doi:10.1097/AOG.0b013e31816102b9

24. Jensen JR, White WM, Coddington CC. Maternal and neonatal complications of elective early-term deliveries. Mayo Clin Proc . 2013;88(11):1312-1317. doi:10.1016/j.mayocp.2013.07.009

25. Wu Y, Kataria Y, Wang Z, Ming WK, Ellervik C. Factors associated with successful vaginal birth after a cesarean section: A systematic review and meta-analysis. BMC Pregnancy Childbirth . 2019;19(1):1-12. doi:10.1186/s12884-019-2517-y 
26. Jastrow N, Roberge S, Gauthier RJ, et al. Effect of birth weight on adverse obstetric outcomes in vaginal birth after cesarean delivery.Obstet Gynecol . 2010;115(2 PART 1):338-343. doi:10.1097/AOG.0b013e3181c915da

27. Elkousy MA, Sammel M, Stevens E, Peipert JF, Macones G. The effect of birth weight on vaginal birth after cesarean delivery success rates. Am J Obstet Gynecol . 2003;188(3):824-830. doi:10.1067/mob.2003.186

28. ACOG. Clinical Management Guidelines for Obstetrician - Gynecologists. Obstet Gynecol . 2019;133(76):168-186.

\begin{tabular}{|c|c|c|c|}
\hline $\begin{array}{l}\text { Table 1: Demographic } \\
\text { and current delivery } \\
\text { characteristics of the } \\
\text { study groups }\end{array}$ & $\begin{array}{l}\text { Table 1: Demographic } \\
\text { and current delivery } \\
\text { characteristics of the } \\
\text { study groups }\end{array}$ & $\begin{array}{l}\text { Table 1: Demographic } \\
\text { and current delivery } \\
\text { characteristics of the } \\
\text { study groups }\end{array}$ & $\begin{array}{l}\text { Table 1: Demographic } \\
\text { and current delivery } \\
\text { characteristics of the } \\
\text { study groups }\end{array}$ \\
\hline & $\begin{array}{l}\text { TOLAC following } 2 \mathrm{CD} \\
\mathrm{N}=485\end{array}$ & $\begin{array}{l}\text { Elective planned } \\
\text { repeated CD N=2234 }\end{array}$ & $\mathrm{p}$ value \\
\hline $\begin{array}{l}\text { Maternal Age } \\
(\text { Mean } \pm \text { SD })\end{array}$ & $34.44 \pm 4.32$ & $33.49 \pm 5.11$ & $<0.01$ \\
\hline $\begin{array}{l}\text { Gravidity (Median, } \\
\text { IQR) }\end{array}$ & $7(6-10)$ & $4(3-6)$ & $<0.01$ \\
\hline Parity (Median, IQR) & $5(4-7)$ & $3(3-5)$ & $<0.01$ \\
\hline $\begin{array}{l}\text { Previous miscarriage } \mathrm{n} \\
(\%)\end{array}$ & $228(47.0 \%)$ & $987(44.2 \%)$ & 0.26 \\
\hline $\begin{array}{l}\text { Fertility treatments } \mathrm{n} \\
(\%)\end{array}$ & $5(1.0 \%)$ & $126(5.6 \%)$ & $<0.01$ \\
\hline Diabetes n $(\%)^{*}$ & $30(6.2 \%)$ & $264(11.8 \%)$ & $<0.01$ \\
\hline $\begin{array}{l}\text { Hypertensive disorders } \\
\text { of pregnancy } \mathrm{n}(\%)^{* *}\end{array}$ & $9(1.9 \%)$ & $111(4.9 \%)$ & $<0.01$ \\
\hline $\begin{array}{l}\text { Multifetal gestation } \mathrm{n} \\
(\%)\end{array}$ & $4(0.8 \%)$ & $24(1.1 \%)$ & 0.62 \\
\hline $\begin{array}{l}\text { BMI }\left(\mathrm{kg} / \mathrm{m}^{2}\right) \\
(\mathrm{Mean} \pm \mathrm{SD})^{* * *}\end{array}$ & $29.58 \pm 4.76$ & $31.24 \pm 5.50$ & $0<0.01$ \\
\hline $\begin{array}{l}\text { Epidural analgesia } n \\
(\%)\end{array}$ & $235(48.5 \%)$ & NA & NA \\
\hline $\begin{array}{l}\text { Intrapartum fever } n \\
(\%)\end{array}$ & $1(0.2 \%)$ & NA & NA \\
\hline Episiotomy n (\%) & $7(1.4 \%)$ & NA & NA \\
\hline $\begin{array}{l}\text { TOLAC - Trail of } \\
\text { labor after cesarean, } \\
\text { CD - cesarean delivery, } \\
\text { SD - standard } \\
\text { deviation, IQR - } \\
\text { interquartile range, NA } \\
\text { - not available }\end{array}$ & $\begin{array}{l}\text { TOLAC - Trail of } \\
\text { labor after cesarean, } \\
\text { CD - cesarean delivery, } \\
\text { SD - standard } \\
\text { deviation, IQR - } \\
\text { interquartile range, NA } \\
\text { - not available }\end{array}$ & $\begin{array}{l}\text { TOLAC - Trail of } \\
\text { labor after cesarean, } \\
\text { CD - cesarean delivery, } \\
\text { SD - standard } \\
\text { deviation, IQR - } \\
\text { interquartile range, NA } \\
\text { - not available }\end{array}$ & $\begin{array}{l}\text { TOLAC - Trail of } \\
\text { labor after cesarean, } \\
\text { CD - cesarean delivery, } \\
\text { SD - standard } \\
\text { deviation, IQR - } \\
\text { interquartile range, NA } \\
\text { - not available }\end{array}$ \\
\hline
\end{tabular}




\begin{tabular}{|c|c|c|c|}
\hline $\begin{array}{l}\text { Table 1: Demographic } \\
\text { and current delivery } \\
\text { characteristics of the } \\
\text { study groups }\end{array}$ & $\begin{array}{l}\text { Table 1: Demographic } \\
\text { and current delivery } \\
\text { characteristics of the } \\
\text { study groups }\end{array}$ & $\begin{array}{l}\text { Table 1: Demographic } \\
\text { and current delivery } \\
\text { characteristics of the } \\
\text { study groups }\end{array}$ & $\begin{array}{l}\text { Table 1: Demographic } \\
\text { and current delivery } \\
\text { characteristics of the } \\
\text { study groups }\end{array}$ \\
\hline $\begin{array}{l}*(\text { pre gestational }+ \\
\text { gestational }) \\
* * \text { Hypertensive } \\
\text { disorders of pregnancy, } \\
\text { a composite of: } \\
\text { gestational } \\
\text { hypertension, } \\
\text { preeclampsia and } \\
\text { eclampsia. }{ }^{* *} \text { Due to } \\
\text { missing data } \mathrm{N}=71 \text { in } \\
\text { TOLAC group and } \\
\mathrm{N}=767 \text { in Elective } \mathrm{CD} \\
\text { group }\end{array}$ & $\begin{array}{l}*(\text { pre gestational }+ \\
\text { gestational }) \\
* * \text { Hypertensive } \\
\text { disorders of pregnancy, } \\
\text { a composite of: } \\
\text { gestational } \\
\text { hypertension, } \\
\text { preeclampsia and } \\
\text { eclampsia. } * * * \text { Due to } \\
\text { missing data } \mathrm{N}=71 \text { in } \\
\text { TOLAC group and } \\
\mathrm{N}=767 \text { in Elective } \mathrm{CD} \\
\text { group }\end{array}$ & $\begin{array}{l}*(\text { pre gestational }+ \\
\text { gestational }) \\
* * \text { Hypertensive } \\
\text { disorders of pregnancy, } \\
\text { a composite of: } \\
\text { gestational } \\
\text { hypertension, } \\
\text { preeclampsia and } \\
\text { eclampsia. } * * * \text { Due to } \\
\text { missing data } \mathrm{N}=71 \text { in } \\
\text { TOLAC group and } \\
\mathrm{N}=767 \text { in Elective } \mathrm{CD} \\
\text { group }\end{array}$ & $\begin{array}{l}* \text { (pre gestational }+ \\
\text { gestational) } \\
* * \text { Hypertensive } \\
\text { disorders of pregnancy, } \\
\text { a composite of: } \\
\text { gestational } \\
\text { hypertension, } \\
\text { preeclampsia and } \\
\text { eclampsia. }{ }^{* * *} \text { Due to } \\
\text { missing data } \mathrm{N}=71 \text { in } \\
\text { TOLAC group and } \\
\mathrm{N}=767 \text { in Elective } \mathrm{CD} \\
\text { group }\end{array}$ \\
\hline
\end{tabular}

\begin{tabular}{|c|c|c|c|c|}
\hline $\begin{array}{l}\text { Table 2: Maternal } \\
\text { and delivery } \\
\text { outcomes of the } \\
\text { study groups. }\end{array}$ & $\begin{array}{l}\text { Table 2: Maternal } \\
\text { and delivery } \\
\text { outcomes of the } \\
\text { study groups. }\end{array}$ & $\begin{array}{l}\text { Table 2: Maternal } \\
\text { and delivery } \\
\text { outcomes of the } \\
\text { study groups. }\end{array}$ & $\begin{array}{l}\text { Table 2: Maternal } \\
\text { and delivery } \\
\text { outcomes of the } \\
\text { study groups. }\end{array}$ & $\begin{array}{l}\text { Table 2: Maternal } \\
\text { and delivery } \\
\text { outcomes of the } \\
\text { study groups. }\end{array}$ \\
\hline & & $\begin{array}{l}\text { TOLAC following } 2 \\
\mathrm{CD} \mathrm{N}=485\end{array}$ & $\begin{array}{l}\text { Elective planned } \\
\text { repeated CD N= } \\
2234\end{array}$ & $\mathrm{P}$ value \\
\hline \multirow[t]{3}{*}{$\begin{array}{l}\text { Mode of delivery } \\
\mathrm{n}(\%)\end{array}$} & $\begin{array}{l}\text { Spontaneous } \\
\text { vaginal }\end{array}$ & $392(80.8 \%)$ & NA & NA \\
\hline & Operative vaginal & $26(5.4 \%)$ & & \\
\hline & Cesarean & $67(13.8 \%)$ & & \\
\hline $\begin{array}{l}\text { Shoulder dystocia } \\
\mathrm{n}(\%)\end{array}$ & $\begin{array}{l}\text { Shoulder dystocia } \\
\mathrm{n}(\%)\end{array}$ & $3(0.6 \%)$ & NA & NA \\
\hline $\begin{array}{l}\text { Postpartum } \\
\text { endometritis } n \\
(\%)\end{array}$ & $\begin{array}{l}\text { Postpartum } \\
\text { endometritis } n \\
(\%)\end{array}$ & $2(0.4 \%)$ & $26(1.2 \%)$ & 0.14 \\
\hline $\begin{array}{l}\text { Postpartum } \\
\text { hemorrhage n (\%) }\end{array}$ & $\begin{array}{l}\text { Postpartum } \\
\text { hemorrhage n (\%) }\end{array}$ & $35(7.2 \%)$ & $167(7.5 \%)$ & 0.84 \\
\hline $\begin{array}{l}\text { Hemoglobin } \\
\text { drop }>4 \mathrm{gr} / \mathrm{dL} \mathrm{n} \\
(\%)\end{array}$ & $\begin{array}{l}\text { Hemoglobin } \\
\text { drop }>4 \text { gr/dL n } \\
(\%)\end{array}$ & $14(2.9 \%)$ & $74(3.3 \%)$ & 0.63 \\
\hline $\begin{array}{l}\text { IV Iron } \\
\text { administration n } \\
(\%)\end{array}$ & $\begin{array}{l}\text { IV Iron } \\
\text { administration n } \\
(\%)\end{array}$ & $0(0.0 \%)$ & $9(0.4 \%)$ & 0.16 \\
\hline $\begin{array}{l}\text { Blood products } \\
\text { transfusion } \mathrm{n}(\%)\end{array}$ & $\begin{array}{l}\text { Blood products } \\
\text { transfusion } \mathrm{n}(\%)\end{array}$ & $8(1.6 \%)$ & $58(2.6 \%)$ & 0.22 \\
\hline $\begin{array}{l}\text { Uterine rupture } \mathrm{n} \\
(\%)\end{array}$ & $\begin{array}{l}\text { Uterine rupture } \mathrm{n} \\
(\%)\end{array}$ & $3(0.6 \%)$ & $3(0.1 \%)$ & 0.04 \\
\hline $\begin{array}{l}\text { Re-laparotomy n } \\
(\%)\end{array}$ & $\begin{array}{l}\text { Re-laparotomy n } \\
(\%)\end{array}$ & $0(0.0 \%)$ & $3(0.1 \%)$ & 0.09 \\
\hline $\begin{array}{l}\text { Hysterectomy n } \\
(\%)\end{array}$ & $\begin{array}{l}\text { Hysterectomy n } \\
(\%)\end{array}$ & $1(0.2 \%)$ & $2(0.1 \%)$ & 0.48 \\
\hline
\end{tabular}




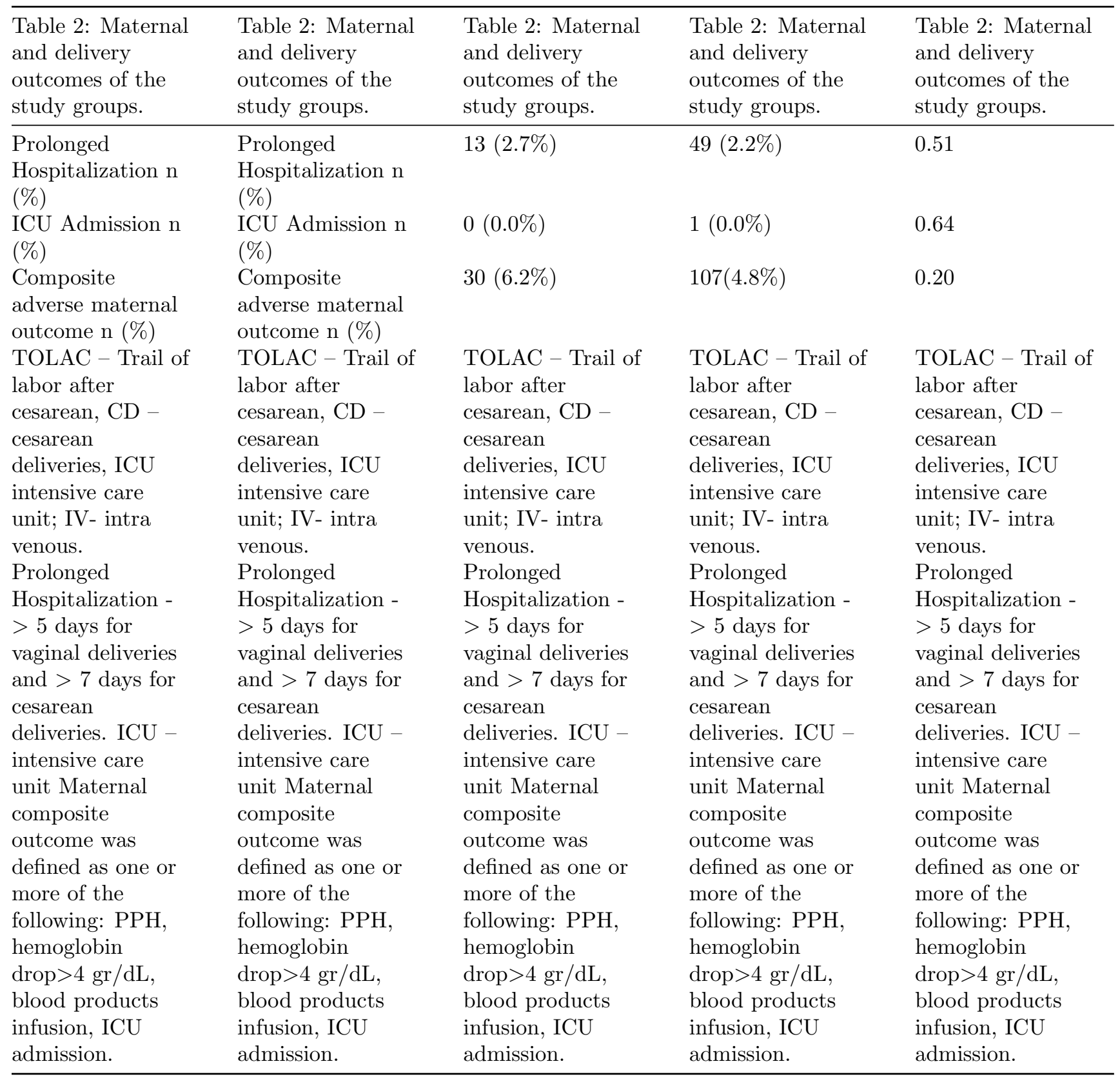

\begin{tabular}{|c|c|c|c|}
\hline $\begin{array}{l}\text { Table } 3 \text { : Neonatal } \\
\text { outcomes of the study } \\
\text { groups }\end{array}$ & $\begin{array}{l}\text { Table 3: Neonatal } \\
\text { outcomes of the study } \\
\text { groups }\end{array}$ & $\begin{array}{l}\text { Table 3: Neonatal } \\
\text { outcomes of the study } \\
\text { groups }\end{array}$ & $\begin{array}{l}\text { Table } 3 \text { : Neonatal } \\
\text { outcomes of the study } \\
\text { groups }\end{array}$ \\
\hline & $\begin{array}{l}\text { TOLAC following } 2 \mathrm{CD} \\
\mathrm{N}=485\end{array}$ & $\begin{array}{l}\text { Elective planned } \\
\text { repeated } \mathrm{CD} \mathrm{N}=2234\end{array}$ & $\mathrm{P}$ value \\
\hline $\begin{array}{l}\text { Gestational age at } \\
\text { delivery, week (Median, } \\
\text { IQR) }\end{array}$ & $40(39-40)$ & $38(38-39)$ & $<0.01$ \\
\hline $\begin{array}{l}\text { Birthweight, grams } \\
(\text { Mean } \pm \text { SD) }\end{array}$ & $3361.2 \pm 585.5$ & $3134.5 \pm 486.4$ & $<0.01$ \\
\hline
\end{tabular}




\begin{tabular}{|c|c|c|c|}
\hline $\begin{array}{l}\text { Table } 3 \text { : Neonatal } \\
\text { outcomes of the study } \\
\text { groups }\end{array}$ & $\begin{array}{l}\text { Table 3: Neonatal } \\
\text { outcomes of the study } \\
\text { groups }\end{array}$ & $\begin{array}{l}\text { Table 3: Neonatal } \\
\text { outcomes of the study } \\
\text { groups }\end{array}$ & $\begin{array}{l}\text { Table 3: Neonatal } \\
\text { outcomes of the study } \\
\text { groups }\end{array}$ \\
\hline $\begin{array}{l}\text { Neonatal gender, male } \\
\mathrm{n}(\%)\end{array}$ & $228(47.0 \%)$ & $1139(51.0 \%)$ & 0.08 \\
\hline $\begin{array}{l}\text { Macrosomia (>4000 } \\
\text { grams) n }(\%)\end{array}$ & $46(9.5 \%)$ & $86(3.8 \%)$ & $<0.01$ \\
\hline $\begin{array}{l}\text { 1-Minute Apgar score } \\
<7 \mathrm{n}(\%)\end{array}$ & $30(6.2 \%)$ & $91(4.1 \%)$ & 0.04 \\
\hline $\begin{array}{l}\text { 5-Minute Apgar score } \\
<7 \mathrm{n}(\%)\end{array}$ & $9(1.9 \%)$ & $45(2.0 \%)$ & 0.82 \\
\hline NICU admission $\mathrm{n}(\%)$ & $23(4.7 \%)$ & $191(8.5 \%)$ & 0.02 \\
\hline $\begin{array}{l}\text { Neonatal asphyxia } \mathrm{n} \\
(\%)\end{array}$ & $0(0.0 \%)$ & $3(0.1 \%)$ & 0.55 \\
\hline TTN n $(\%)$ & $10(2.1 \%)$ & $52(2.3 \%)$ & 0.72 \\
\hline $\begin{array}{l}\text { Mechanical ventilation } \\
\mathrm{n}(\%)\end{array}$ & $12(2.5 \%)$ & $36(1.6 \%)$ & 0.19 \\
\hline $\begin{array}{l}\text { Composite adverse } \\
\text { neonatal outcome } \mathrm{n} \\
(\%)\end{array}$ & $30(6.2 \%)$ & $245(11.0 \%)$ & $<0.01$ \\
\hline $\begin{array}{l}\text { TOLAC - Trail of } \\
\text { labor after cesarean, } \\
\text { CD - cesarean } \\
\text { deliveries, SD - } \\
\text { standard deviation }\end{array}$ & $\begin{array}{l}\text { TOLAC - Trail of } \\
\text { labor after cesarean, } \\
\text { CD - cesarean } \\
\text { deliveries, SD - } \\
\text { standard deviation }\end{array}$ & $\begin{array}{l}\text { TOLAC - Trail of } \\
\text { labor after cesarean, } \\
\text { CD - cesarean } \\
\text { deliveries, SD - } \\
\text { standard deviation }\end{array}$ & $\begin{array}{l}\text { TOLAC - Trail of } \\
\text { labor after cesarean, } \\
\text { CD - cesarean } \\
\text { deliveries, SD - } \\
\text { standard deviation }\end{array}$ \\
\hline $\begin{array}{l}\text { NICU Neonatal } \\
\text { intensive care unit, } \\
\text { TTN transient } \\
\text { tachypnea of the } \\
\text { newborn }\end{array}$ & $\begin{array}{l}\text { NICU Neonatal } \\
\text { intensive care unit, } \\
\text { TTN transient } \\
\text { tachypnea of the } \\
\text { newborn }\end{array}$ & $\begin{array}{l}\text { NICU Neonatal } \\
\text { intensive care unit, } \\
\text { TTN transient } \\
\text { tachypnea of the } \\
\text { newborn }\end{array}$ & $\begin{array}{l}\text { NICU Neonatal } \\
\text { intensive care unit, } \\
\text { TTN transient } \\
\text { tachypnea of the } \\
\text { newborn }\end{array}$ \\
\hline $\begin{array}{l}\text { Neonatal composite } \\
\text { outcome was defined as } \\
\text { one or more of the } \\
\text { following: 5-min Apgar } \\
<7 \text {, asphyxia, NICU } \\
\text { admission or the need } \\
\text { for mechanical } \\
\text { ventilation }\end{array}$ & $\begin{array}{l}\text { Neonatal composite } \\
\text { outcome was defined as } \\
\text { one or more of the } \\
\text { following: } 5 \text {-min Apgar } \\
<7 \text {, asphyxia, NICU } \\
\text { admission or the need } \\
\text { for mechanical } \\
\text { ventilation }\end{array}$ & $\begin{array}{l}\text { Neonatal composite } \\
\text { outcome was defined as } \\
\text { one or more of the } \\
\text { following: } 5 \text {-min Apgar } \\
<7 \text {, asphyxia, NICU } \\
\text { admission or the need } \\
\text { for mechanical } \\
\text { ventilation }\end{array}$ & $\begin{array}{l}\text { Neonatal composite } \\
\text { outcome was defined as } \\
\text { one or more of the } \\
\text { following: } 5 \text {-min Apgar } \\
<7 \text {, asphyxia, NICU } \\
\text { admission or the need } \\
\text { for mechanical } \\
\text { ventilation }\end{array}$ \\
\hline
\end{tabular}

Table 4: Composite adverse Neonatal outcome following 2 CD, elective CD vs. TOLAC; results from multivariate analysis

Variables

In labor CD

Meconium aspiration

Gestational age at delivery

Macrosomia (>4000 grams)

TOLAC vs. Planned elective CD

Hypertensive disorders of pregnancy**

Diabetes*

Parity 
Table 4: Composite adverse Neonatal outcome following 2 CD, elective CD vs. TOLAC; results from multivariate analysis $\mathrm{CD}$ - cesarean delivery, TOLAC - trail of labor after cesarean, aOR- adjusted odds ratio, CI - confidence interval. $*($ pre ge

Figure 1: Flow chart of the study group

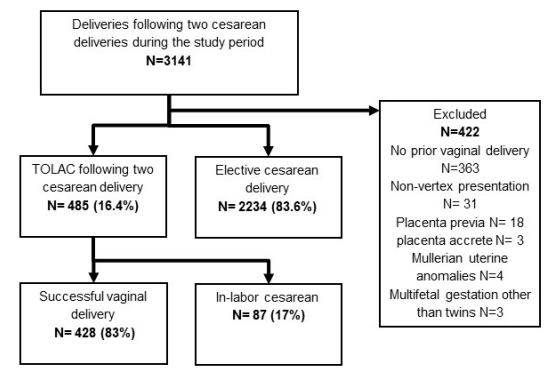

